\title{
STUDY OF THE EFFECT OF THE ELECTROLESS NI-P COATING THICKNESS APPLIED ON AW-7075 ALUMINUM ALLOY ON ITS MECHANICAL PROPERTIES
}

\author{
Kazimierz Czapczyk ${ }^{1}$, Piotr Siwak' ${ }^{1}$, Stanislaw Legutko'
}

\begin{abstract}
1 Poznan University of Technology, Faculty of Mechanical Engineering and Management, Piotrowo 3, 60-965 Poznan, Poland, e-mail: kazimierz.czapczyk@doctorate.put.poznan.pl, piotr.siwak@put.poznan.pl, stanislaw. legutko@put.poznan.pl
\end{abstract}

Received: 2018.04.19

Accepted: 2018.05.11

Published: 2018.06.01

\begin{abstract}
The paper presents the results of examination of microhardness of chemical coatings $\mathrm{Ni}-\mathrm{P}$, applied on samples of aluminium alloy for plastic processing AW-7075. The examinations have been performed on samples with three different thicknesses of the Ni-P coatings; next the influence of their thickness on the depth of material penetration by the indenter under load, as well as its influence on creep, increase of Martens hardness and on the Young's modulus of the system of the coating with the substrate material. Hardness measurements have been performed with the use of PICODENTOR HM500 nanohardness tester (Vickers). The purpose of the examination of Ni-P coating deformation without dispersion phases is analysis of their mechanical properties in respect of the possibility of technical applications on the aluminium alloy AW-7075 (among others, by the selection of optimum thicknesses on hard aluminium alloy), as well as the determination of the possibility of applying dispersion phases in order to improve their properties.
\end{abstract}

Keywords: Ni-P coating, Martens hardness, creep, Young's modulus, aluminium alloy.

\section{INTRODUCTION}

Ni-P coatings made by the method of chemical reduction can be laid on various materials, including constructional ones, due to their mechanical properties. Thanks to that, they have found many technical applications. An important advantage of them is even distribution on the substrate surfaces regardless of their shape which is precisely projected during the coat application and they significantly improve adherence and durability as compared to electrolytic coatings. Moreover, they can be ground for coatings of, for example, much higher hardness which cannot be applied directly on any material or they can be enriched with dispersion phases in order to improve their abrasive wear resistance. An example of materials to which it is difficult to select coatings with increased abrasion resistance and high adherence is aluminium alloys. The most often applied coatings are ones which have anticorrosion properties or ones which form a decorative layer. In the case of aluminium alloys, the most popular operations are anodizing (hard or soft oxide coatings, e.g. in order to protect against corrosion and mechanical damages or for decoration), possibly colouring process of anodizing etc. Chemical Ni-P coatings can be put on practically each material, including aluminium alloys, significantly improving mechanical properties of the surface, which increases the possibilities of application of aluminium alloys in the machine industry $[10,6,12]$. Properly selected combination of layers or coating composition for a given application can have many advantages, e.g. reduction of the mass of individual machine parts by substitution of steel, extension of tool life $[4,8]$ as compared to alumin- 
ium alloys without coatings, improvement of their efficiency $[13,9]$ and reduction of inertia. Due to the fact that most of machine parts manufactured at the moment require operations improving their mechanical properties [5], selection of anti-wear coatings has become necessary [7]. Thanks to the development of coatings and the technology of applying them, many parts can be provided with higher load capacity without the necessity of using heavier and/or larger materials. The existing applications of electrolytic coatings, mostly for anticorrosion and decorative purposes, have inspired designers and scientists to elaborate better coatings to meet the requirements related to better strength, hardness, adherence to the substrate.

The present study is aimed at the determination of the changes of the mechanical properties of chemical Ni-P coatings on AW-7075 aluminium alloys depending on their thickness.

\section{GENERAL DESCRIPTION OF THE NI-P CHEMICAL COATING}

The material of the chemical Ni-P coating is unique due to the method of application and properties. The nickel-phosphor coatings are amorphic, homogenous, relatively brittle, selflubricating, easy to solder and have good corrosion resistance. Moreover, they can be successfully subjected to precipitation hardening. Due to that nickel-phosphor coatings are suitable for many applications.

The hardness of the nickel-phosphor coating applied by the current less method is about 500 $-600 \mathrm{HV}$. During heat treatment consisting in ageing at the temperature of $340^{\circ} \mathrm{C}$ for 2 hours, the coating hardness increases up to as much as $1100 \mathrm{HV}$. The nickel-phosphor coatings applied by the current less method have good abrasive wear resistance, both just after application and in the hardened condition [3].

Compared to the coatings applied by the electrolytic method, the coatings obtained by the chemical method show the following major advantages:

- the Ni-P coating forms a layer of the same thickness on all the surfaces reached by the bath regardless of the shape of the coated object,
- the coating structure is even and independent of the substrate structure,

- they show higher hardness which can be increased by later heat treatment,

- they show better corrosion resistance,

- they can be applied directly on aluminium,

- they show good solder ability.

The process of chemical depositing significantly extends the scope of application of the Ni-P coatings, however, for economic reasons, it has some drawbacks, too:

- the cost of the chemical bath components is higher than in the case of the electrolytic bath,

- the largest difficulty in wide application of chemical depositing is regeneration of the bath [14].

Considering the possibilities of using the Ni-P coating on aluminium alloys for technical applications, taking into account the properties, advantages and tests performed so far, the coating should be further tested in the application for machine parts which had been made of AW-7075 aluminium alloy.

\section{METHODOLOGY OF INVESTIGATION}

Ni-P coatings deposited by the method of chemical reduction on aluminium alloy, AW-7075 with the hardness of about $155 \mathrm{HV}$. The Young's modulus of the alloy is $72 \mathrm{GPa}$ and its chemical composition can be found in Table 1.

Samples in the form of cubicoids dimensioned $15 \times 15 \times 7 \mathrm{~mm}$ have been coated with chemical Ni-P coatings with the thicknesses of $10 \mu \mathrm{m}, 20$ $\mu \mathrm{m}$ and $30 \mu \mathrm{m}$. (Fig. 1). Prior to that, the samples have been ground with fine grained abrasive paper with the gradation of 1200 . The coatings on the samples have been made by GALVO S.A. company in Lodz where special electrolytic baths have been applied. Once deposited, the coatings have been subjected to internal quality control in order to confirm their thickness and quality.

The mechanical properties of the coatings have been examined on the laboratory device, PICODENTOR HM500 in the Faculty of Mechanical Engineering and Management of the Poznan University of Technology. The examination has been

Table 1. Chemical composition of the AW-7075 alloy

\begin{tabular}{|c|c|c|c|c|c|c|c|c|c|c|}
\hline $\mathbf{A l}$ & $\mathbf{Z n}$ & $\mathbf{M g}$ & $\mathbf{C u}$ & $\mathbf{F e}$ & $\mathbf{S i}$ & $\mathbf{M n}$ & $\mathbf{C r}$ & $\mathbf{Z r}$ & $\mathrm{Ti}$ & Other \\
\hline Balance & $5.10-6.10$ & $2.10-2.90$ & $1.20-2.00$ & $\max 0.50$ & $\max 0.40$ & $\max 0.30$ & $0,18-0.28$ & $\max 0.25$ & $\max 0.20$ & $\max 0.05$ \\
\hline
\end{tabular}




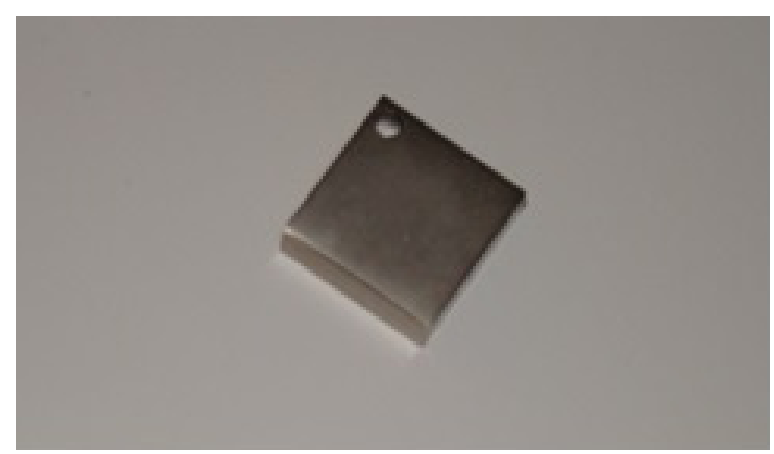

Fig. 1. AW-7075 alloy sample with current less Ni-P coating

performed by applying the force of $300 \mathrm{mN}$ for 20 seconds to the laboratory machine indenter according to European Norm PN-EN ISO 6507-1:1999; 6 measurements have been performed on the samples at even distances in several rows and maintaining the distance of minimum $2 \mathrm{~mm}$ from the edge (Fig. 2). There were prepared 3 samples for each thickness of Ni-P coating separately. The parameters measured during the examination were: plastic stress, creep, Martens hardness [11] and Young's modulus. Moreover, basing on the obtained computer diagrams, the depth of the indenter penetration of the materials has been determined.

The coating thicknesses have been selected considering their internal stresses because, the increase of thickness results in the increase of tensile stress which is detrimental and significantly reduce durability, usability and functionality of the coatings. On the other hand, the greater compressive stress the better adherence of the coating and its crack resistance, resistance to exfoliation and other mechanical damages. Unfortunately, compressive stresses occur with small thicknesses and that is why 10,20 and $30 \mu \mathrm{m}$ have been selected although it was possible to make much thicker coatings (even as thick as $120 \mu \mathrm{m}$ ).

\section{TEST RESULTS}

Average measurement results can be found in Table 2 .

In order to ensure good adhesion of the deposited layers, the oxide layer had to be removed from the surface of the AW-7075 alloy constituting the substrate. The oxide layer is removed in a process

Table 2. The results of examination of mechanical properties of the surface of chemical Ni-P coating deposited on AW 7075 aluminium alloy

\begin{tabular}{|c|c|c|c|c|}
\hline $\begin{array}{c}\text { Coating thickness } \\
(\boldsymbol{\mu m})\end{array}$ & $\begin{array}{c}\text { Indenter penetration depth } \\
(\boldsymbol{\mu m})\end{array}$ & $\begin{array}{c}\text { E - Young's modulus } \\
(\mathbf{G P a})\end{array}$ & $\begin{array}{c}\text { HM - Martens micro- } \\
\text { hardness of the coating } \\
(\mathbf{N} / \mathbf{m m} \mathbf{)})\end{array}$ & $\begin{array}{c}\text { Creep during the } \\
\text { indenter pressing } \\
(\%)\end{array}$ \\
\hline 10 & 1.08 & 129.50 & 4049.44 & 1.165 \\
\hline 20 & 0.99 & 151.92 & 4845.02 & 1.020 \\
\hline 30 & 0.87 & 180.73 & 5976.23 & 1.048 \\
\hline
\end{tabular}
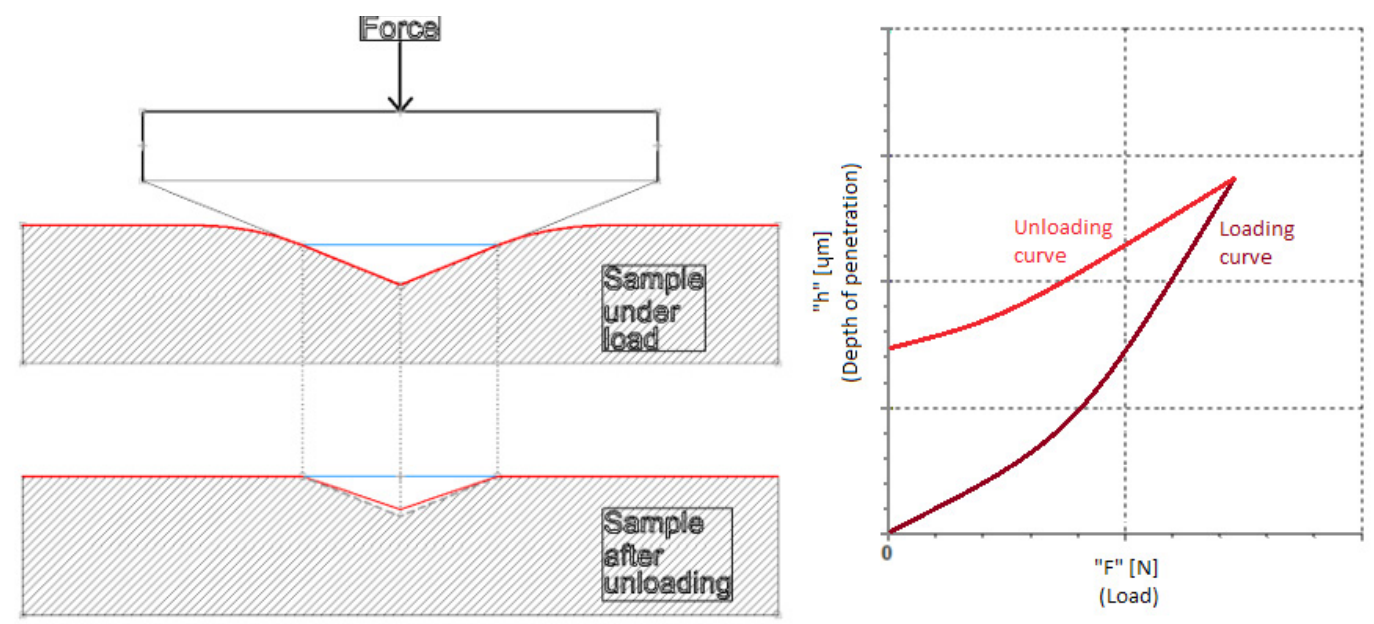

Fig. 2. Theoretical diagram of the material penetration by the laboratory indenter together with the diagram of the load dependence on the penetration depth (A - Vickers indenter) 

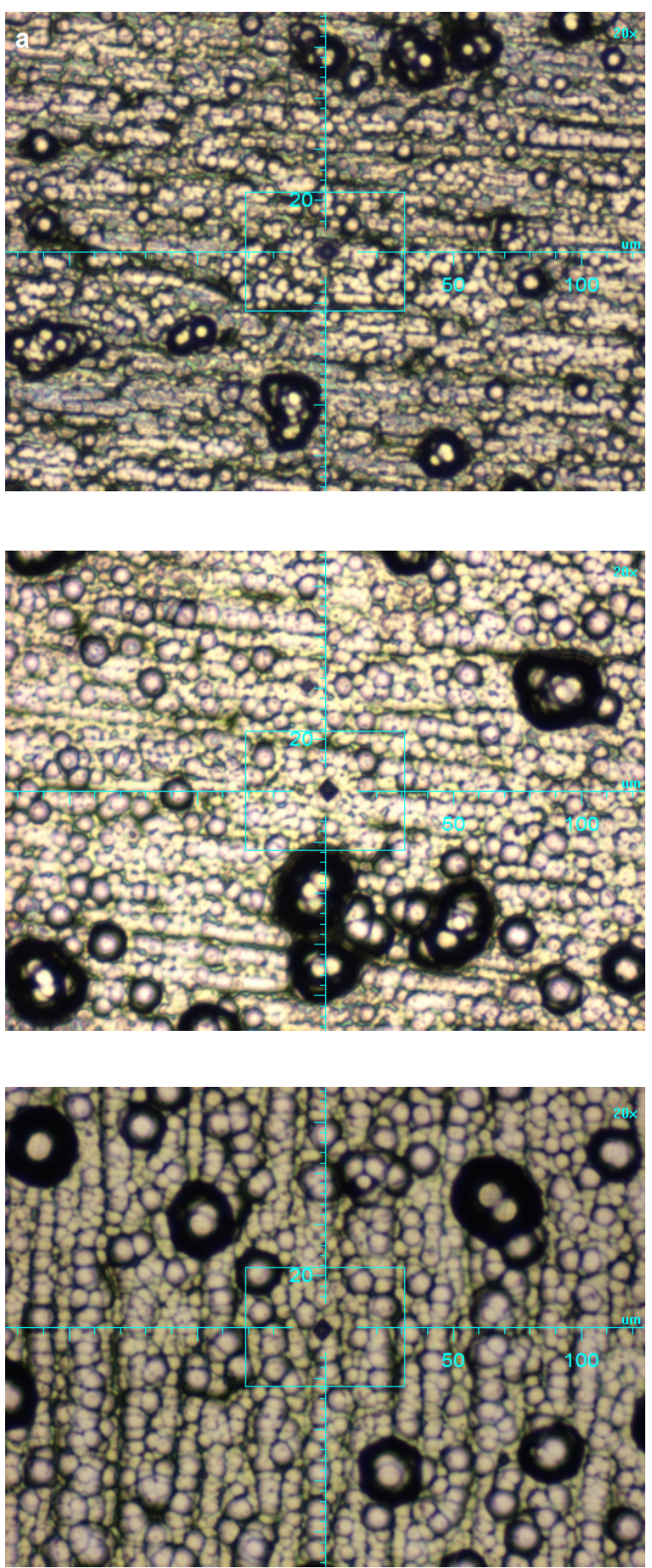

Fig. 3. Morphology of the Ni-P layer with various thicknesses on the surface of AW 7075 aluminium alloy: a) $10 \mu \mathrm{m}$, b) $20 \mu \mathrm{m}$, c) $30 \mu \mathrm{m}$

of etching, but it is immediately rebuilt as result of aluminium passivation. In order to remove such a layer, the substrate surface has been subjected to zinc plating, which resulted in removal of the passivating oxide layer and formation of a thin layer of zinc on the surface, ensuring good conection of the coating with the substrate [2]. It has been
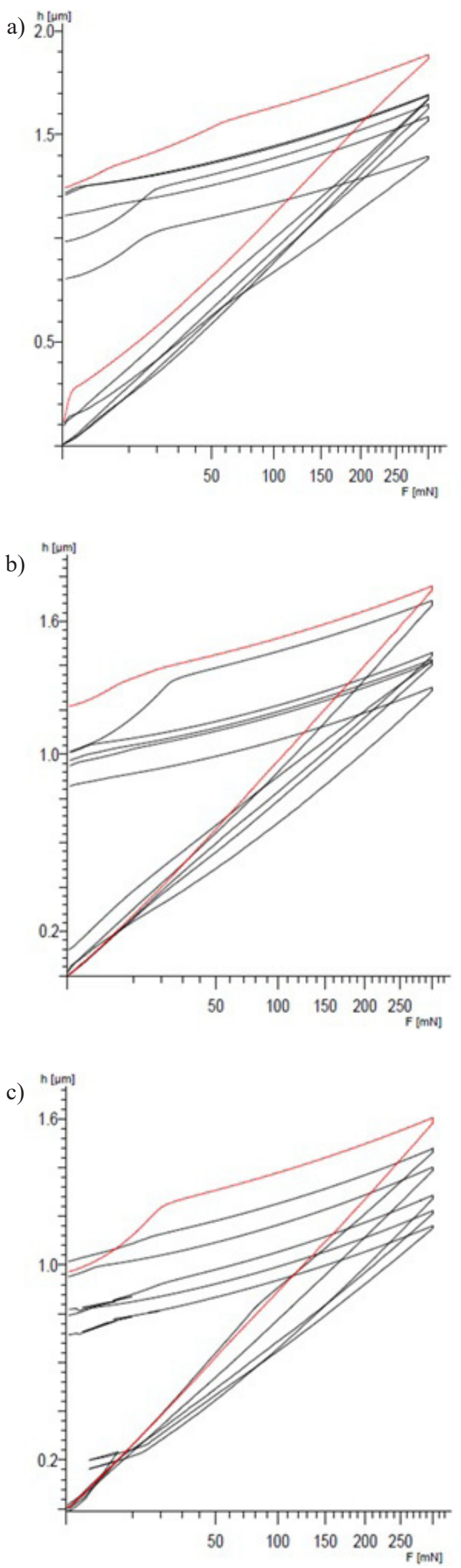

Fig. 4. The dependence of laboratory indenter penetration depth on the force loading the coating a) 10 $\mu \mathrm{m}$, b) $20 \mu \mathrm{m}$, c) $30 \mu \mathrm{m}$ 


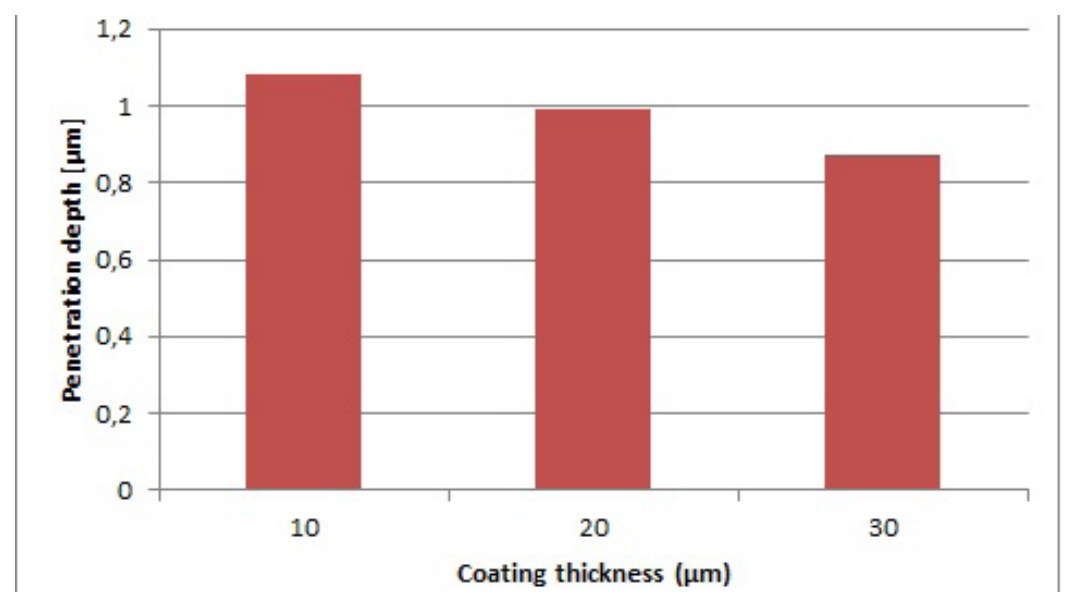

Fig. 5. The depth of Ni-P coating penetration on the aluminium alloy, AW-7075, as a function of its thickness

observed that the deposited zinc uniformly covers the surface of aluminium. On the AW-7075 alloy surfaces prepared in this way, Ni-P coatings of various thicknesses have been deposited; images of those coatings can be seen in Figure 3.

The morphologies of Ni-P layers seems the same for all of samples, as it was expected, because the structure for them is also the same in spite of the different thickness. In fact, no defects or damages of surfaces were noticed, especially in areas where the measurements have been done.

The first parameter to be examined was the depth of the indenter penetration into the Ni-P coatings made on the AW-7075 aluminium alloy (Fig. 4). The test results from Table 2 show that the depths of the impressions after unloading the indenter decrease clearly and gradually. This is directly due to the increase of the coating hardness with the increase of their thickness on softer substrate. The hardness is directly related to the thickness and that is why the changes of the penetration depth also depend on the coating thickness (Fig. 5).

The coating penetration test results have shown its drop with the increase of their thickness. For a $20 \mu \mathrm{m}$ thick Ni-P coating the material penetration has dropped by about $8.3 \%$ as compared to $10 \mu \mathrm{m}$ thick coating; for the thickest 30 $\mu \mathrm{m}$ coating, the depth has dropped by $12.1 \%$ as compared to $20 \mu \mathrm{m}$ thick coating; for a $10 \mu \mathrm{m}$ coating by $19.4 \%$.

The Young's modulus (E), or coefficient of longitudinal elasticity, expressed as the dependence of the linear true strain $(\varepsilon)$, on the stress, $\sigma$, which appears in the range of elastic deformations (applicability of Hooke's law) is considered to be one of the most important parameters characterizing materials. The dependence of proportional deformations which occur at the applied stretching (compressing) force have been determined by Hooke's law and, thanks to it, one can determine a material elasticity using the mentioned Young's modulus (E). Each material has its own physical properties and, when building responsible constructions supposed to carry high loads, the designers select materials with adequate strength, resistant to high internal stresses with minimum deformation - that is why the higher Young's modulus the larger stresses the given material can carry.

A similar principle is valid for isotropic coatings. However, in the case under investigation, we consider the system of the chemical Ni-P coating with the substrate and the smaller coating thickness the bigger influence of the substrate on the measurement result. With the increase of the Ni-P coating thickness, the Young's modulus gradually increases from the value of 129.5 up to $180.73 \mathrm{GPa}$. To compare, for the AW-7075 aluminium alloy alone, the coefficient of proportionality is $72 \mathrm{GPa}$. The highest value obtained in the test appears with the biggest Ni-P layer thickness and is very close to that for its material because, in that case, the substrate influence is much smaller. As compared to the AW-7075 alloy, significant increase of the coefficient of proportionality is observed and, basing on the analysis of those results, the coating material alone could carry much higher loads than the aluminium alloy if, theoretically, such samples made of pure Ni-P existed. Unfortunately, it is not possible from the point of view of electroplating, however, coating with Young's modulus much 


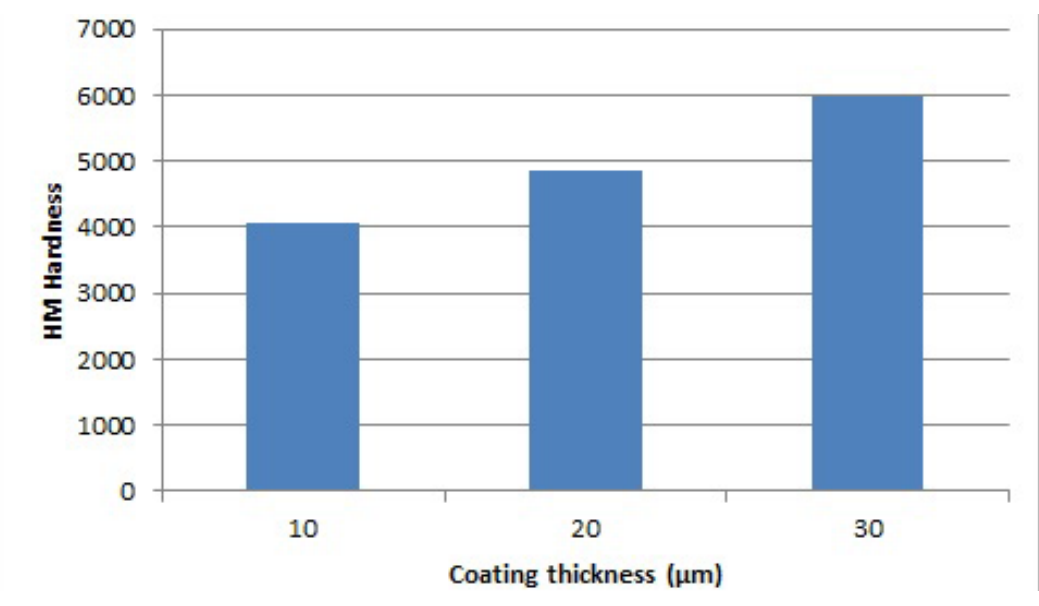

Fig. 6. The measurement results of Martens hardness of the Ni-P coating on AW-7075 aluminium alloy

higher than that of the substrate, theoretically makes larger load possible, which results in the possibility of increasing the carrying capacity of the given part - neglecting other factors and parameters influencing the coating behaviour. The third parameter under consideration was Martens microhardness (HM) for the coatings made directly on the AW-7075 aluminium alloys with the substrate material. Average measurement results are shown in Table 2. Hardness changes have been graphically presented in Figure 6 .

Microhardness measurement examinations have shown gradual increase of the hardness of the coating top layers with the increase of their thickness. For an Ni-P coating with the thickness of $20 \mu \mathrm{m}$, increase of about $19.6 \%$ as compared to the coating with $10 \mu \mathrm{m}$ thickness has $\mu \mathrm{m}$ obtained. In the case of the thickest $(30 \mu \mathrm{m})$ coating, increases of $23.3 \%$ and $47.5 \%$ have been obtained as compared to the thickness of $20 \mu \mathrm{m}$ and $10 \mu \mathrm{m}$ respectively.

A fourth parameter, creep, has also been examined. This is a phenomenon consisting in slow change of material deformation under the influence of long nesting loads below the material limit of elasticity [14]. All the average values are in the region of $1 \%$. However, more precise analysis of the individual measurements shows that they vary within the ranges of $0.97 \div 1.35$ for $10 \mu \mathrm{m}$, $1 \div 1.35$ for $20 \mu \mathrm{m}$ and $0.84 \div 1.34$ for $30 \mu \mathrm{m}$. In the test, linear .load has been applied and the tests have been performed with the same loading speed for each thickness. In accordance with [1], the creep value increases with the speed of loading within definite ranges corresponding to the given material. It can be stated, therefore, that, under the predetermined laboratory conditions, with the adopted load of $300 \mathrm{mN}$ (in a period of $20 \mathrm{~s}$ ), the coating thickness changes have not significantly influenced the value of the parameter of creeping determining the process of plastic deformation related to very low deformation speed. If only the coating material were processed, its limit of creeping could be determined, as well as creep resistance in tensile test. However, for the system of AW-7075 aluminium alloy with the Ni-P coating, the results indicate very small deformation.

\section{CONCLUSIONS}

Basing on the performed investigation, the following conclusions can be formulated:

- The coating thicknesses influence the hardness of the top layer. The hardnesses have been measured on the surface of the samples and the values increase proportionally in relation to the increase of the coating thickness, from the level of about $4000 \mathrm{HM}$ to 6000 $\mathrm{HM}$, i.e. for the transitions from 10 to $20 \mu \mathrm{m}$ and from 20 to $30 \mu \mathrm{m}$, the hardness values increase by about $20 \%$.

- The bigger thickness of the coating, the higher its deformation resistance. This is proved by the results of the measurements of the Ni-P coating penetration depth which decreases gradually by about $10 \%$ with simultaneous increase of their thickness by $10 \mu \mathrm{m}$.

- The material constant - Young's modulus (E) was also changing gradually and noticeably and its increases have been observed at the levels of about $17.3 \%$ and $18.9 \%$. The strength of the coatings is a very complex issue, however, if their strength theoretically 
depended mainly on the Young's modulus, the obtained results would indicate the possibility of adequately larger loads for the individual coatings with adequate thickness. Theoretically, much higher internal stresses can be obtained with appearing simultaneous minimum deformation of the coatings as compared to the substrate material (AW7075) with much lower Young's modulus $(\mathrm{E}=72 \mathrm{GPa})$ because the higher Young's modulus the higher stress can be carried by the given material. Increase of the Young's modulus is, therefore, very advantageous for the Ni-P coating.

- The test results concerning the phenomenon of creeping for the Ni-P coatings have shown the lack of clear influence of their thickness on the process of plastic deformation with very low deformation speed.

\section{REFERENCES}

1. Bijak-Żochowski M., Jaworski A., Krzesiński G., Zagrajek T.: Mechanika materiałów i konstrukcji Tom 1. Oficyna Wydawnicza Politechniki Warszawskiej, Warszawa 2006.

2. Bijak-Żochowski M., Jaworski A., Krzesiński G., Zagrajek T.: Mechanika materiałów i konstrukcji Tom 2. Oficyna Wydawnicza Politechniki Warszawskiej, Warszawa 2006.

3. Blicharski M.: Inżynieria powierzchni. WNT, Warszawa 2012.

4. Krolczyk G., Legutko S., Raos P.: Cutting wedge wear examination during turning of duplex stainless steel. Tehnički Vjesnik - Technical Gazette, 20, 3/2013, pp. 413-418.

5. Krolczyk G., Legutko S., Stoic A.: Influence of cutting parameters and conditions onto surface hardness of duplex stainless steel after turning process.
Tehnički Vjesnik - Technical Gazette, 20, 6/2013, pp. 1077-1080.

6. Kwiatkowski L., Tomassi P.: Powłoki konwersyjne na blachach aluminiowych - technologie wytwarzania i metody badań. Inżynieria Powierzchni, 1/2009, pp. 36-45.

7. Maruda R. W., Krolczyk G. M., Feldshtein E., Nieslony P., Tyliszczak B., Pusavec F.: Tool wear characterizations in finish turning of AISI 1045 carbon steel for MQCL conditions. Wear, 372373/2017, pp. 54-67.

8. Maruda R. W., Krolczyk G.M., Nieslony P., Wojciechowski S., Michalski M., Legutko S.: The influence of the cooling conditions on the cutting tool wear and the chip formation mechanism. Journal of Manufacturing Processes, 24/2016, pp. 107 - 115.

9. Nieslony P., Cichosz P., Krolczyk G.M., Legutko S., Smyczek D., Kolodziej M.: Experimental studies of the cutting force and surface morphology of explosively clad $\mathrm{Ti}-$ steel plates. Measurement, 78/2016, pp. 129 - 137.

10. Ozimina D., Madej M., Senatorski J.: Wytwarzanie przeciwzużyciowych warstw powierzchniowych typu Ni-P- $\mathrm{Al}_{2} \mathrm{O}_{3}$. Inżynieria Powierzchni, 4/2006, pp. 13-19.

11. Pokorska I.: Wpływ szybkości obciążenia na twardość wyznaczaną metodą DSI. Inżynieria Powierzchni, vol. 32, 4/2011, pp. 672-675.

12. Trzaska M.: Warstwy kompozytowe Ni-P/Si3N4 wytwarzane metodą chemiczną na aluminium i jego stopach. Inżynieria Materiałowa, vol. 29, 6/2008, pp. 657-660.

13. Wojciechowski S., Maruda R. W., Nieslony P., Krolczyk G.M.: Investigation on the edge forces in ball end milling of hardened steel, International Journal of Mechanical Sciences. $119 / 2016$, pp. $360-369$.

14. Żak T.: Poradnik galwanotechnika. WNT, Warszawa 1985. 